\title{
Unsteady Micropolar Fluid over a Permeable Curved Stretching Shrinking Surface
}

\author{
Siti Hidayah Muhad Saleh, ${ }^{1}$ Norihan Md Arifin, ${ }^{1,2}$ Roslinda Nazar, ${ }^{3}$ and Ioan Pop ${ }^{4}$ \\ ${ }^{1}$ Department of Mathematics, Faculty of Science, Universiti Putra Malaysia (UPM), 43400 Serdang, Selangor, Malaysia \\ ${ }^{2}$ Institute For Mathematical Research, Universiti Putra Malaysia (UPM), 43400 Serdang, Selangor, Malaysia \\ ${ }^{3}$ School of Mathematical Sciences, Faculty of Science and Technology, Universiti Kebangsaan Malaysia (UKM), \\ 43600 Bangi, Selangor, Malaysia \\ ${ }^{4}$ Department of Mathematics, Babeş-Bolyai University, 400084 Cluj-Napoca, Romania
}

Correspondence should be addressed to Norihan Md Arifin; norihanarifin@yahoo.com

Received 26 September 2016; Accepted 15 December 2016; Published 20 February 2017

Academic Editor: Mohammad D. Aliyu

Copyright (c) 2017 Siti Hidayah Muhad Saleh et al. This is an open access article distributed under the Creative Commons Attribution License, which permits unrestricted use, distribution, and reproduction in any medium, provided the original work is properly cited.

\begin{abstract}
This work deals with the unsteady micropolar fluid over a permeable curved stretching and shrinking surface. Using similarity transformations, the governing boundary layer equations are transformed into the nonlinear ordinary (similarity) differential equations. The transformed equations are then solved numerically using the shooting method. The effects of the governing parameters on the skin friction and couple stress are illustrated graphically. The results reveal that dual solutions exist for stretching/shrinking surface as well as weak/strong concentration. A comparison with known results from the open literature has been done and it is shown to be in excellent agreement.
\end{abstract}

\section{Introduction}

The fundamental nature of the theory of micropolar fluid flow lies in the extension of the constitutive equations for Newtonian fluids, so that more complex fluid such as particle suspensions, liquid crystals, animal blood, and turbulent shear flows can be expressed by this theory. The micropolar fluid theory which takes into account the inertial characteristics of the substructure particles which are permitted to endure rotation has been intended by Eringen [1] and was further discussed by Eringen [2]. This theory has caused much attention and many aspects of flows being reexamined to verify the effect of the fluid microstructure. A detailed study on the applications of microcontinuum fluid mechanics has been accessed by Ariman et al. [3]. Since then, many other studies related to the ideas of micropolar fluid have been done. Ahmadi [4] analyzed self-similar solution for incompressible micropolar flow over semi-infinite plate. A study on stagnation flows of micropolar fluids with strong and weak interactions was reported by Guram and Smith [5]. Then, it seems Gorla [6] has obtained numerical results for the micropolar boundary layer flow at a stagnation point on moving wall using fourth-order Runge Kutta method.

During the past several years considerable interest has been verified in the study of steady and unsteady flows of a viscous incompressible fluid determined by a linearly stretching surface through a quiescent fluid. Such flow situations are encountered in a number of manufacturing practices, such as the cooling of metallic plate in a cooling bath, polymer sheet extrusion, and heat-treated materials that are on a conveyor belt. Crane [7] found a closedform exact solution for a two-dimensional laminar flow of an incompressible viscous fluid over a linearly stretching sheet, and Wang [8] discovered similarity solutions for the axisymmetric case. In another paper, Wang [9] has analyzed the viscous flow due to a stretching sheet with surface slip and suction. The combination of both stagnation point-flows past a stretching surface was solved numerically by Mahapatra and Gupta $[10,11]$ and analytically by Mahapatra et al. [12]. The effects of radiation with magnetic field on stretching sheet were obtained by Mat Yasin et al. [13]. Also, in a very interesting recently published paper, Turkyilmazoglu [14] has 
mathematically resolved the domain of existence for magnetohydrodynamic mixed convection flow of a micropolar fluid past a heated or cooled stretching permeable surface by taking into account the heat generation and absorption effects. Furthermore, few studies have been done on the reaction of permeable stretching sheet in nanofluid which was conducted by Ibrahim and Shankar [15], Bachok et al. [16], and Zaimi et al. [17]. Moreover, Turkyilmazoglu [18] analyzed the flow of a micropolar fluid due to a porous stretching sheet and heat transfer.

Furthermore, the work on boundary layer flow due to a shrinking sheet has also attracted much interest. It seems that Miklavčič and Wang [19] investigated the flow over a shrinking sheet and found an exact solution of the NavierStokes equations. It was discovered that mass suction is needed to sustain the flow over a shrinking sheet. From physical point of view, vorticity of the shrinking sheet is not restricted within a boundary layer, and the flow is improbable to subsist unless an adequate suction on the boundary is discussed [19]. Further, the velocity of the shrinking sheet is confined in the boundary layer with stagnation flow was discovered by Wang [20]. This new type of shrinking sheet flow is fundamentally a backward flow as discussed by Goldstein [21]. On the other hand, Turkyilmazoglu [22] has analytically studied the steady flow of micropolar fluid and heat transfer over a shrinking sheet under porous wall conditions. He has verified mathematically the bounds of multiple existing solutions of purely exponential kind. It is worth mentioning that the importance and new results on the flow induced by a shrinking sheet in a various fluid and geometrical approach were recently presented by Rosali et al. [23], Naramgari and Sulochana [24], Merkin et al. [25], and Soid et al. [26]. In addition, Roşca and Pop [27] investigated combined effects of micropolar fluid towards a permeable shrinking sheet in the presence of slip effect and Aurangzaib et al. [28] extend it with MHD mixed convection effects. Next, a study of the viscous flow over a shrinking sheet analytically solved using a second-order slip flow model was by Fang et al. [29] where they obtained that the result has two branches, or dual solutions, in a certain range of the parameters, while Bhattacharyya et al. [30] studied that the velocity and thermal boundary layer thicknesses for the second solutions are always larger than the first solutions.

Instead of plane boundary layer, there has been growing interest in the study of the effects of curvature by several investigators recently. Few papers have been discussed on this topic and found that its presence inside the boundary layer is no more negligible as in the case of a flat stretching sheet. Sajid et al. [33] considered stretching curved surface viscous fluid flow and discovered that the boundary layer thickness increases for a curved surface compared to flat surface. Moreover, the drag force to move the liquid on curved surface is less than on a flat surface. Then, they extend the problem to micropolar fluid (see Sajid et al. [34]). Abbas et al. [31] discussed the heat transfer analysis by considering the two heat processes, namely, prescribed surface temperature and described heat flux on MHD boundary layer flow on a curved stretching surface. Further, they continued with slip effect with generation and thermal radiation in
Abbas et al. [35]. Homogeneous-heterogeneous reactions in MHD flow due to an unsteady curved stretching surface were being observed by Imtiaz et al. [36].

It is worth mentioning that there are also many examples of unsteady flow and in fact, there is no real flow situation, natural or artificial, that does not occupy some unsteadiness. The flows in all manufacturing applications were randomly assumed to be steady. In many engineering instruments, unsteadiness is an integral part of the problem. The helicopter rotor, the cascades of turbomachinery blade, the ship propeller, and so forth usually work in an unsteady environment. Most of the elementary ideas of unsteady viscous flows are described by Telionis [37]. Quite different flow behavior is observed for an unsteady shrinking sheet that is for an unsteady stretching sheet. Roşca and Pop [32] performed a study on the unsteady boundary layer flow over a permeable curved stretching/shrinking sheet. Boundary layer flow of a viscous fluid over an unsteady curved stretching sheet with magnetic field is discussed by Naveed et al. [38].

The aim of the present paper is to study the flow problem due to the unsteady plane, two-dimensional laminar flow caused by a permeable curved stretching/shrinking sheet in a micropolar fluid. The governing partial differential equations are first transformed into a system of ordinary differential equations, before being solved numerically. The expressions for the skin friction coefficients and couple stress coefficients, including velocity and microrotation velocity, are determined to understand the flow characteristics. It is hoped that the results obtained will not only provide useful information for applications, but also serve as a complement to the previous studies. To the best of our knowledge these results are new and original.

\section{Basic Equations}

Consider the unsteady two-dimensional boundary layer flow of a micropolar fluid over a permeable curved stretching/shrinking surface coiled in a circle of radius $R$ about the curvilinear coordinates $r$ and $s$, where $r$ is normal to tangent vector at any point on the surface and $s$ is the arc length coordinate along the flow direction, as depicted in Figure 1(a), so that large values of $R$ represent a slightly curved sheet. The geometry for the stretching and shrinking sheet is shown in Figures 1(b) and 1(c), respectively. A constant magnetic field, $B_{0}$, is applied in the $r$-direction. By assuming that the magnetic Reynolds number is low, thus, we have neglected the effects of induced magnetic field. Also the applied electric field is assumed to be zero. Moreover, it is assumed that the surface is stretched/shrinked with the velocity $u_{w}(s)$ along the $s$-direction. It should be mentioned that $v_{w}(t, s)$ is the mass flux velocity, where $v_{w}(t, s)<0$ corresponds to suction and $v_{w}(t, s)>0$ corresponds to injection, respectively, and $t$ is the time.

Under these assumptions along with the boundary layer approximations, the governing equations for the flow are discussed by Abbas et al. [31] and Roşca and Pop [32],

$$
\frac{\partial}{\partial r}[(r+R) v]+R \frac{\partial u}{\partial s}=0
$$




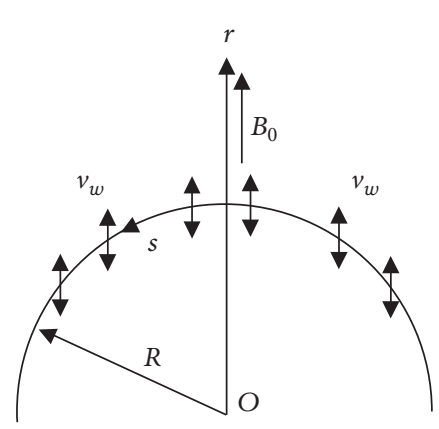

(a)

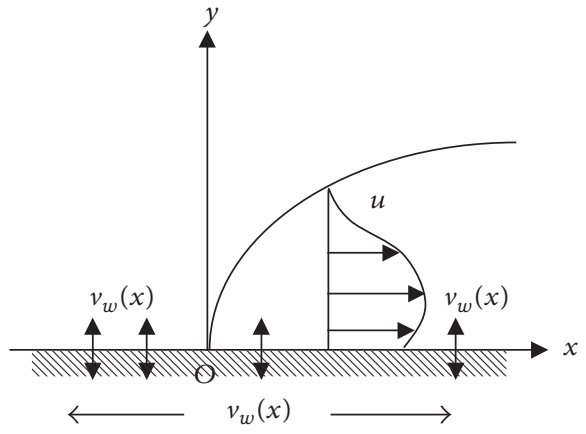

(b)

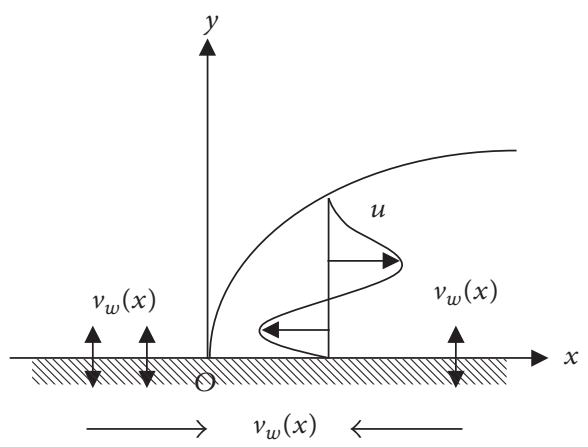

(c)

FIgURE 1: Physical model and coordinate system: (a) curvature surface; (b) stretching surface; (c) shrinking surface.

$$
\begin{aligned}
\frac{u^{2}}{r+R} & =\frac{1}{\rho} \frac{\partial p}{\partial r} \\
\frac{\partial u}{\partial t}+ & v \frac{\partial u}{\partial r}+\frac{R u}{r+R} \frac{\partial u}{\partial s}+\frac{u v}{r+R} \\
= & -\frac{1}{\rho} \frac{R}{r+R} \frac{\partial p}{\partial s} \\
& +\left(v+\frac{k^{*}}{\rho}\right)\left[\frac{\partial^{2} u}{\partial r^{2}}+\frac{1}{r+R} \frac{\partial u}{\partial r}-\frac{u}{(r+R)^{2}}\right] \\
& -\frac{k^{*}}{\rho} \frac{\partial N}{\partial r} \\
\frac{\partial N}{\partial t}+ & v \frac{\partial N}{\partial r}+\frac{R u}{r+R} \frac{\partial N}{\partial s} \\
= & -\frac{\gamma}{\rho j}\left(\frac{\partial^{2} N}{\partial r^{2}}+\frac{1}{r+R} \frac{\partial N}{\partial r}\right) \\
& -\frac{k^{*}}{\rho j}\left(2 N+\frac{\partial u}{\partial r}+\frac{u}{r+R}\right),
\end{aligned}
$$

where $v$ and $u$ are the velocity components along $r$ - and $s$ directions, respectively, $p$ is the pressure, $\rho$ is the density, and $\nu$ is the kinematic viscosity. Here, $\gamma$ is assumed to be

$$
\gamma=\left(\mu+\frac{k^{*}}{2}\right) j=\mu\left(1+\frac{K}{2}\right) j, \quad j=\frac{\nu}{a},
$$

where $K=k^{*} / \mu$ is the micropolar or material parameter.

The initial and boundary conditions applicable to the flow are

$$
\begin{aligned}
t<0: & v=u=N=0 \\
t \geq 0: & v=v_{w}, \\
u & =\lambda \frac{u_{w} s}{1-\alpha t}=\lambda \frac{a s}{1-\alpha t}, \\
N & =-n \frac{\partial u}{\partial r}
\end{aligned}
$$

$$
\begin{aligned}
& u \longrightarrow 0, \\
& \frac{\partial u}{\partial r} \longrightarrow 0, \\
& N \longrightarrow 0,
\end{aligned}
$$

as $r \longrightarrow \infty$,

where $a$ is a positive constant, $\lambda$ is the dimensionless constant stretching $(\lambda>0)$ or shrinking $(\lambda<0)$ parameter, respectively, $\alpha>0$ is for an accelerated surface and $\alpha<$ 0 is for a decelerated surface, respectively, and $u_{w}(s)=$ as. Further, $n$ is a constant which varies in the range of $0 \leq n \leq 1$. It is also noted that the case $n=0$ is called strong concentration and indicates $N=0$ near the wall and represents concentrated particle flows in which the microelements close to the wall surface are unable to rotate. The case $n=0.5$ indicates the vanishing of antisymmetric part of the stress tensor and denotes weak concentrations. The case $n=1$ is used for the modeling turbulent flows. In the present paper, we are interested in the laminar flow configuration; therefore, we consider only strong and weak concentrations of microelements.

We will introduce now the similarity variables defined as

$$
\begin{aligned}
u & =\frac{a s}{1-\alpha t} f^{\prime}(\eta), \\
v & =-\frac{R}{r+R} \sqrt{\frac{a v}{1-\alpha t}} f(\eta), \\
N & =\frac{a s}{1-\alpha t} \sqrt{\frac{a}{\nu(1-\alpha t)}}, \\
p & =\frac{\rho a^{2} s^{2}}{(1-\alpha t)^{2}} P(\eta), \\
\eta & =\sqrt{\frac{a}{v(1-\alpha t)}} r,
\end{aligned}
$$

where prime denotes differentiation with respect to $\eta$. Thus, we take

$$
v_{w}=-\sqrt{\frac{a \nu}{1-\alpha t}} S,
$$


where $S$ is the constant wall mass transfer, with $S>0$ for suction and $S<0$ for injection, respectively.

Substituting (4) into (1), we get the following system of ordinary differential equations:

$$
\begin{aligned}
& P^{\prime}=\frac{f^{\prime 2}}{\eta+k} \\
& \frac{2 k}{\eta+k} P=(1+K)\left[f^{\prime \prime \prime}+\frac{f^{\prime \prime}}{\eta+k}-\frac{f^{\prime}}{(\eta+k)^{2}}\right] \\
& \quad-\frac{k}{\eta+k} f^{\prime 2}+\frac{k}{\eta+k} f f^{\prime \prime}+\frac{k}{(\eta+k)^{2}} f f^{\prime}-K g^{\prime} \\
& \quad-\beta\left(\frac{\eta}{2} f^{\prime \prime}+f^{\prime}\right) \\
& \left(1+\frac{K}{2}\right)\left(g^{\prime \prime}+\frac{g^{\prime}}{\eta+k}\right)+\frac{k}{\eta+k} f g^{\prime}-\frac{k}{\eta+k} f^{\prime} g \\
& \quad-K\left(2 g+f^{\prime \prime}+\frac{f^{\prime}}{\eta+k}\right)+\frac{\beta}{2}\left(\eta g^{\prime}+3 g\right)=0
\end{aligned}
$$

subject to the boundary conditions

$$
\begin{gathered}
f(0)=S, \\
f^{\prime}(0)=\lambda, \\
g(0)=-n f^{\prime \prime}, \\
f^{\prime}(\eta)=0, \\
f^{\prime \prime}(\eta)=0 \\
g(\eta)=0
\end{gathered}
$$

$$
\text { as } \eta \longrightarrow \infty \text {, }
$$

where $k=R \sqrt{a / \nu(1-\alpha t)}$ is the curvature parameter, which depends on the variable $t$. However the parameter $k$ should be constant, so that we assume $R=R_{0} \sqrt{1-\alpha t}$, where $R_{0}$ is the characteristic radius of the curved surface. Thus, $k=R_{0} \sqrt{a / v}$ is the constant dimensionless curvature parameter and $\beta=$ $\alpha / a$ is the unsteadiness parameter. For the current work, we assume a decelerating shrinking sheet with $\beta \leq 0$.

Eliminating the pressure $P$ from (6) and (7), we have

$$
\begin{aligned}
& (1+K)\left(f^{i v}+\frac{2 f^{\prime \prime \prime}}{\eta+k}-\frac{f^{\prime \prime}}{(\eta+k)^{2}}+\frac{f^{\prime}}{(\eta+k)^{3}}\right) \\
& -\frac{k}{\eta+k}\left(f^{\prime} f^{\prime \prime}-f f^{\prime \prime \prime}\right)-\frac{k}{(\eta+k)^{2}}\left(f^{\prime 2}-f f^{\prime \prime}\right)
\end{aligned}
$$

$$
\begin{aligned}
& -\frac{k}{(\eta+k)^{3}} f f^{\prime}-K\left(g^{\prime \prime}+\frac{g^{\prime}}{\eta+k}\right) \\
& -\frac{\beta}{\eta+k}\left(f^{\prime}+\frac{\eta}{2} f^{\prime \prime}\right)-\frac{\beta}{2}\left(3 f^{\prime \prime}+\eta f^{\prime \prime \prime}\right)=0
\end{aligned}
$$

$$
\begin{array}{r}
\left(1+\frac{K}{2}\right)\left(g^{\prime \prime}+\frac{g^{\prime}}{\eta+k}\right)+\frac{k}{\eta+k} f g^{\prime}-\frac{k}{\eta+k} f^{\prime} g \\
-K\left(2 g+f^{\prime \prime}+\frac{f^{\prime}}{\eta+k}\right)-\frac{\beta}{2}\left(\eta g^{\prime}+3 g\right)=0
\end{array}
$$

subject to boundary condition

$$
\begin{aligned}
f(0) & =S, \\
f^{\prime}(0) & =\lambda, \\
g(0) & =-n f^{\prime \prime}, \\
f^{\prime}(\eta) & =0, \\
f^{\prime \prime}(\eta) & =0, \\
g(\eta) & =0
\end{aligned}
$$

$$
\text { as } \eta \longrightarrow \infty \text {. }
$$

The pressure $P$ can now be determined from (7) as

$$
\begin{aligned}
P(\eta) & =\frac{\eta+k}{2 k}(1+K) \\
& {\left[\begin{array}{c}
\left(\frac{f^{\prime \prime \prime}}{\eta+k}+\frac{f^{\prime \prime}}{(\eta+k)^{2}}-\frac{f^{\prime}}{(\eta+k)^{3}}\right)-\frac{k}{\eta+k} f^{\prime 2}+\frac{k}{\eta+k} f f^{\prime \prime} \\
+\frac{k}{(\eta+k)^{2}} f f^{\prime}-K g^{\prime}-M^{2} f^{\prime}-\beta\left(\frac{\eta}{2} f^{\prime \prime}+f^{\prime}\right)
\end{array}\right] . }
\end{aligned}
$$

It is significant to point out that the result for flat surface can be obtained with $k \rightarrow \infty$. The skin friction coefficient and couple stress coefficient are given as

$$
\begin{aligned}
C_{f} \operatorname{Re}_{x}^{1 / 2} & =(1+K)\left(f^{\prime \prime}(0)+\frac{\lambda}{k}\right) \\
C_{m} \operatorname{Re}_{x} & =\left(1+\frac{K}{2}\right)\left(g^{\prime}(0)-n \frac{f^{\prime \prime}(0)}{k}\right) .
\end{aligned}
$$

\section{Result and Discussion}

The arrangement of ordinary differential equations (10) and (11) subject to the boundary condition (12) has been solved numerically using shooting method with the aid of shootlib function in Maple software for several values of $n, k, K, \beta$, $S$, and $\lambda$. Table 1 shows the comparison of the skin friction coefficient for several values of $k$ when $S=K=\beta=0$ and $\lambda=1$ (stretching) with those reported by Abbas et al. [31] and Roşca and Pop [32]. It can be observed from Table 1 that the results are in good agreement which verify the accuracy of the present method. In addition, Table 2 
TABLE 1: Comparison of results of the skin friction coefficient $-C_{f} \operatorname{Re}_{x}{ }^{1 / 2}$ for several values of $k$ when $S=K=\beta=0$ and $\lambda=1$ (stretching).

\begin{tabular}{lccc}
\hline$k$ & Abbas et al. [31] & $\begin{array}{c}-C_{f} \operatorname{Re}_{x}{ }^{1 / 2} \\
\text { Roşca \& Pop [32] }\end{array}$ & Present results \\
\hline 5 & 1.15763 & 1.15076 & 1.15167 \\
10 & 1.07349 & 1.07172 & 1.07348 \\
20 & 1.03561 & 1.03501 & 1.03505 \\
30 & 1.02353 & 1.02315 & 1.02317 \\
40 & 1.01759 & 1.01729 & 1.01731 \\
50 & 1.01405 & 1.01380 & 1.01381 \\
100 & 1.00704 & 1.00687 & 1.00687 \\
200 & 1.00356 & 1.00342 & 1.00342 \\
1000 & 1.00079 & 1.00068 & 1.00068 \\
$\infty$ & 1.00000 & 1.00000 & 1.00000 \\
\hline
\end{tabular}

TABLE 2: Comparison of results of $f^{\prime \prime}(0)$ for several values of $\lambda(<0)$ when $k \rightarrow \infty, K=\beta=0$, and $S=2$.

\begin{tabular}{lccc}
\hline$\lambda$ & \multicolumn{2}{c}{ Roşca \& Pop [32] } & Present results \\
\hline-0.5 & 0.85289 & 0.85355 & 0.853645 \\
-0.6 & 0.9786 & 0.97947 & 0.979663 \\
-0.7 & 1.08255 & 1.08340 & 1.083821 \\
-0.75 & 1.12366 & 1.125 & 1.125639 \\
-0.8 & 1.15619 & 1.15777 & 1.158798 \\
-0.9 & 1.18214 & 1.18460 & 1.187963 \\
-0.95 & 1.15876 & 1.16242 & 1.163404 \\
-0.99 & 1.08018 & 1.089 & 1.094483 \\
\hline
\end{tabular}

also provides the comparison values of $f^{\prime \prime}(0)$ for shrinking case by Roşca and Pop [32]. In Table 3, we display a sample of our results for skin friction coefficient and couple stress coefficient corresponding to different values of $K$ and $\lambda$ for strong and weak concentrations. Computations are carried out for the following values of the governing parameter both for the weak concentration $(n=0)$ and for the strong concentration $(n=0.5)$ cases: $\lambda=-0.1,0,0.1 ; K=0,0.5,1$; $S=1.5,2,3$; and $\beta=-1,-2,-3$. It will be seen later in the graphical result that dual solutions exist but only on certain range.

Variations of skin friction coefficient and couple stress coefficient with $\lambda$ for different values of $K$ are presented in Figures 2 and 3 for $n=0$ (strong concentration) while Figures 4 and 5 are for $n=0.5$ (weak concentration). It can be seen from these figures that dual solutions exist for each value of considered $K$, while for $\lambda$ equals a certain value, say $\lambda=\lambda_{c}(c=1,2,3)$, where $\lambda_{c}$ is the critical values of $\lambda$, there is unique solution, and when $\lambda<\lambda_{c}$, there is no solution. Dual solutions are obtained when $\lambda>\lambda_{c}$. The first solution is stable, while the second solution is not, according to the stability analysis performed by Weidman et al. [39]; that is, first solution is physically realizable (stable), while the second solution is not physically realizable (unstable). Also, this investigation confirms that the existence and uniqueness

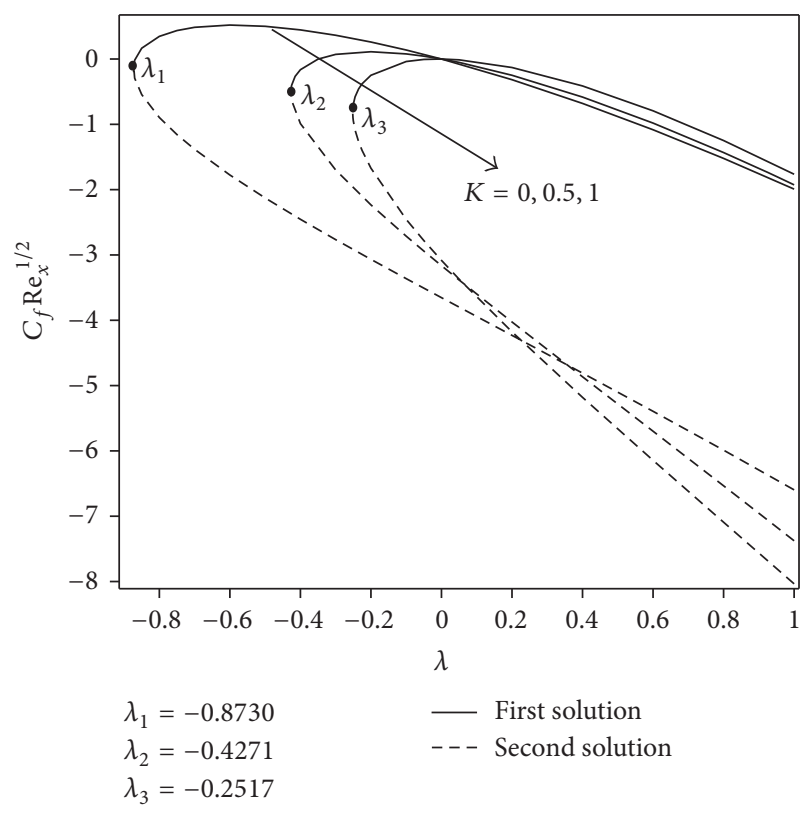

FIGURE 2: Variation of $C_{f} \operatorname{Re}_{x}{ }^{1 / 2}$ with $\lambda$ for several values of $K$ when $S=2, \beta=-2, k=50$, and $n=0$ (strong concentration).

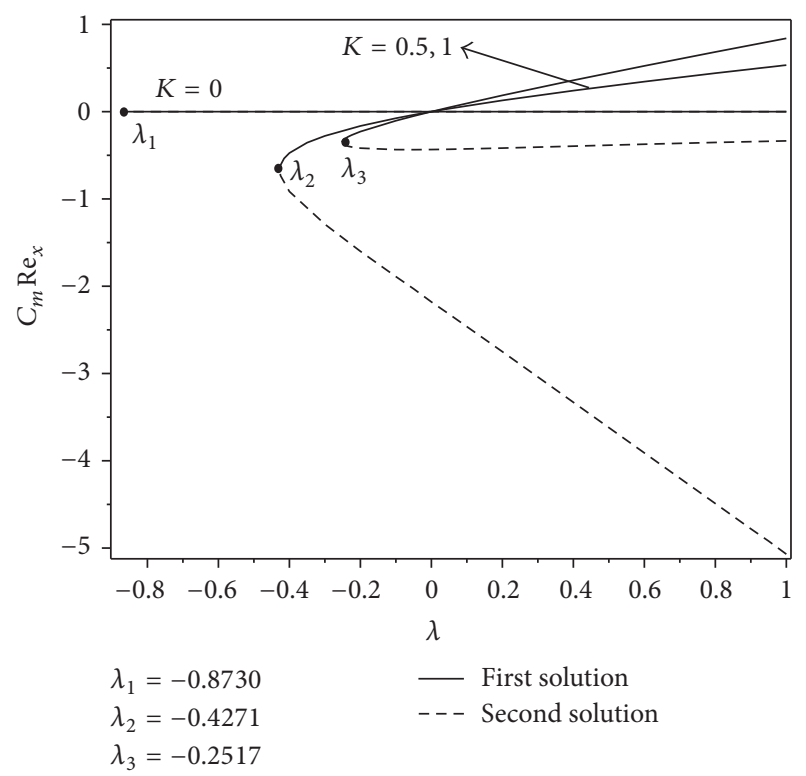

Figure 3: Variation of $C_{m} \operatorname{Re}_{x}$ with $\lambda$ for several values of $K$ when $S=2, \beta=-2, k=50$, and $n=0$ (strong concentration).

of the solutions greatly depend on the stretching/shrinking velocity parameter $\lambda$ as also pointed out by Wang [20]. In addition, we can see the effects of $K$ from Figures 2-5. From these figures, similar influences have been detected for both weak and strong concentration where values of skin friction and couple stress coefficient decrease when $K$ increase for shrinking case and increase with $K$ for stretching case.

Next, the influence of $k$ and $S$ on the skin friction and couple stress coefficient when $n=0.5$ can be examined in Figures 6 and 7, respectively. We noticed that dual solutions 
TABLE 3: Values of skin friction coefficient $-C_{f} \operatorname{Re}_{x}{ }^{1 / 2}$ and couple stress coefficient $C_{m} \operatorname{Re}_{x}$ for several values of $k$ when $S=2, \beta=-2$, and $k=50$.

\begin{tabular}{|c|c|c|c|c|c|c|}
\hline \multirow{2}{*}{$n$} & \multirow[t]{2}{*}{$\lambda$} & \multirow{2}{*}{$K$} & \multicolumn{2}{|c|}{$-C_{f} \operatorname{Re}_{x}{ }^{1 / 2}$} & \multicolumn{2}{|c|}{$C_{m} \operatorname{Re}_{x}$} \\
\hline & & & First solution & Second solution & First solution & Second solution \\
\hline \multirow{6}{*}{0} & \multirow{3}{*}{0.1} & 0 & 0.1540 & 3.9449 & 0 & 0 \\
\hline & & 0.5 & 0.0758 & 2.4016 & 0.0538 & -1.9700 \\
\hline & & 1 & 0.0220 & 1.8236 & 0.0639 & -0.2848 \\
\hline & \multirow{3}{*}{-0.1} & 0 & -0.1399 & 3.3605 & 0 & 0 \\
\hline & & 0.5 & -0.0541 & 1.8061 & -0.0603 & -0.0151 \\
\hline & & 1 & 0.0171 & 1.2277 & -0.0694 & -0.2900 \\
\hline \multirow{6}{*}{0.5} & \multirow{3}{*}{0.1} & 0 & 0.1540 & 3.9449 & -0.0585 & -3.8600 \\
\hline & & 0.5 & 0.0581 & 2.3542 & 0.0201 & -2.6500 \\
\hline & & 1 & 0.0152 & 1.7232 & 0.0531 & -1.2444 \\
\hline & \multirow{3}{*}{-0.1} & 0 & -0.1399 & 3.3605 & 0.0344 & -3.4800 \\
\hline & & 0.5 & -0.0396 & 1.8630 & -0.0416 & -2.0500 \\
\hline & & 1 & 0.0107 & 1.2846 & -0.0761 & -1.0167 \\
\hline
\end{tabular}

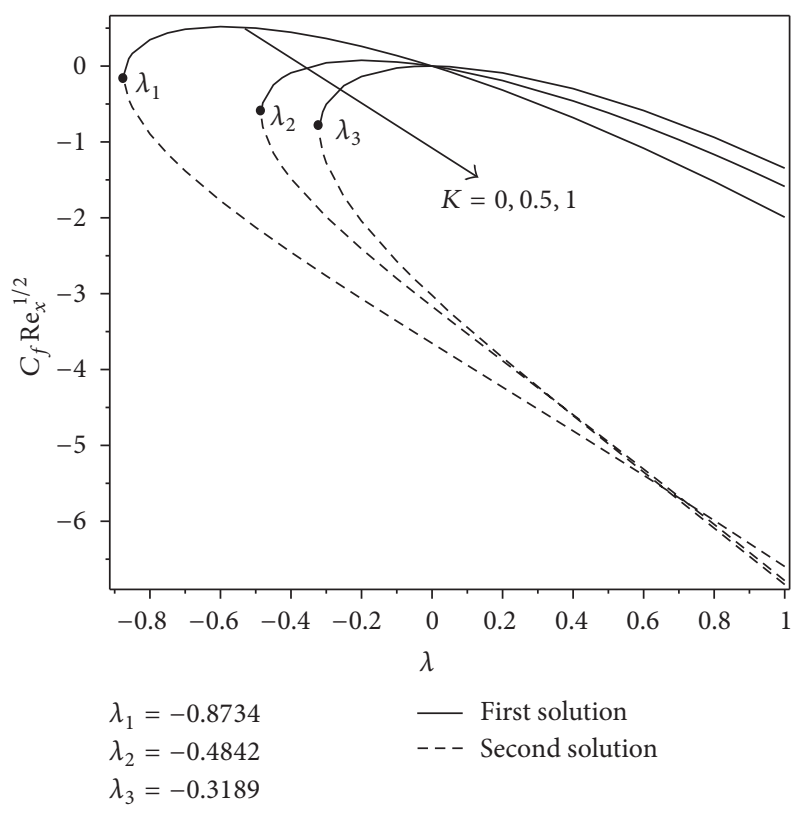

Figure 4: Variation of $C_{f} \operatorname{Re}_{x}{ }^{1 / 2}$ with $\lambda$ for several values of $K$ when $S=2, \beta=-2, k=50$, and $n=0.5$ (weak concentration).

exist when $S>S_{c}(c=1,2,3)$ and no solutions exist for $S<S_{c}(c=1,2,3)$, where $S_{c}$ is the critical value of $S$, a point where first and second solution meet. The values of $S_{c}$ increase as $k$ increase. This result was different for normal viscous fluid where the values of $S_{c}$ decrease with $k$ as reported by Roşca and Pop [32]. Furthermore, Figures 6 and 7 explained that both skin friction and couple stress coefficient slightly increase when $S$ increase. Figures 8 and 9 depict the variations of the skin friction and couple stress coefficient with the unsteadiness parameter, $\beta$, for several values of $k$ when $n=0$ (strong concentration) and $\lambda=-0.1$ (shrinking case). Both figures indicate the dual solutions exist for the range of $\beta>$ $\beta_{c}(c=1,2,3)$, where $\beta=\beta_{c}$ is the critical point where both solutions merge with one another. It also figured that no

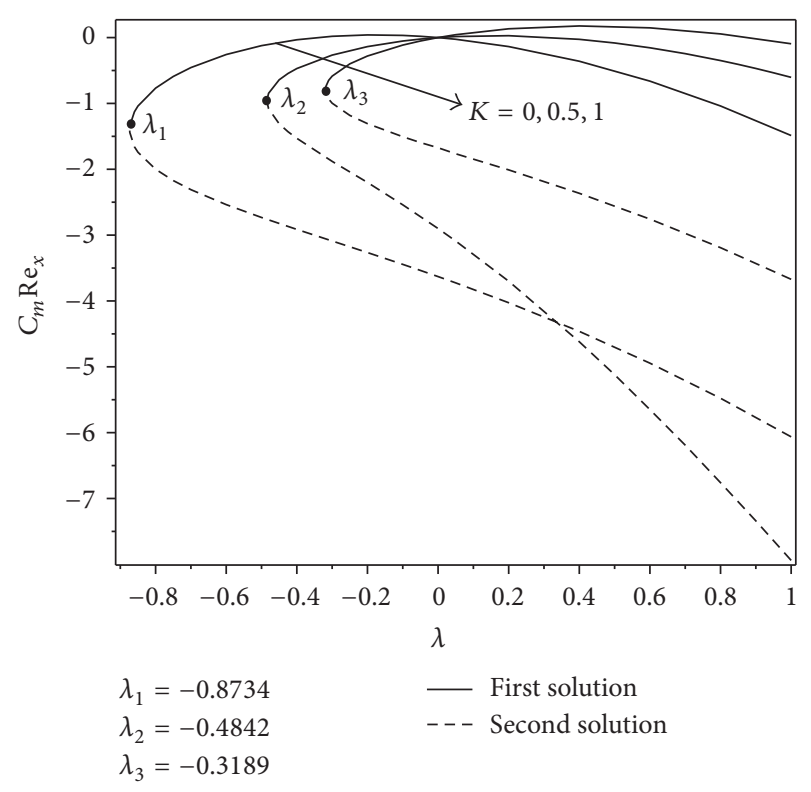

Figure 5: Variation of $C_{m} \operatorname{Re}_{x}$ with $\lambda$ for several values of $K$ when $S=2, \beta=-2, k=50$, and $n=0.5$ (weak concentration).

solution exists at the range of $\beta<\beta_{c}(c=1,2,3)$. Moreover, the figures show the values of skin friction and couple stress coefficient increase when $\beta$ increase. Likewise, similar effect happens as the value of $k$ increases. It is worth pointing out that as $k \rightarrow \infty$, it represents the sheet which is not curved and hence, a bigger force is needed to move the fluid on the flat surface than the curved surface.

The effects of each governing parameter to the velocity profile, $f^{\prime}(\eta)$, as well as microrotation velocity profile, $g(\eta)$, are presented in Figures 10-19. It is worth mentioning that effects of $n$ on velocity profiles are depicted in the same figure since they just have a slight difference compared to their effects on microrotation velocity profiles. Figure 10 shows the influence of $K$ on velocity profile and it shows that the 


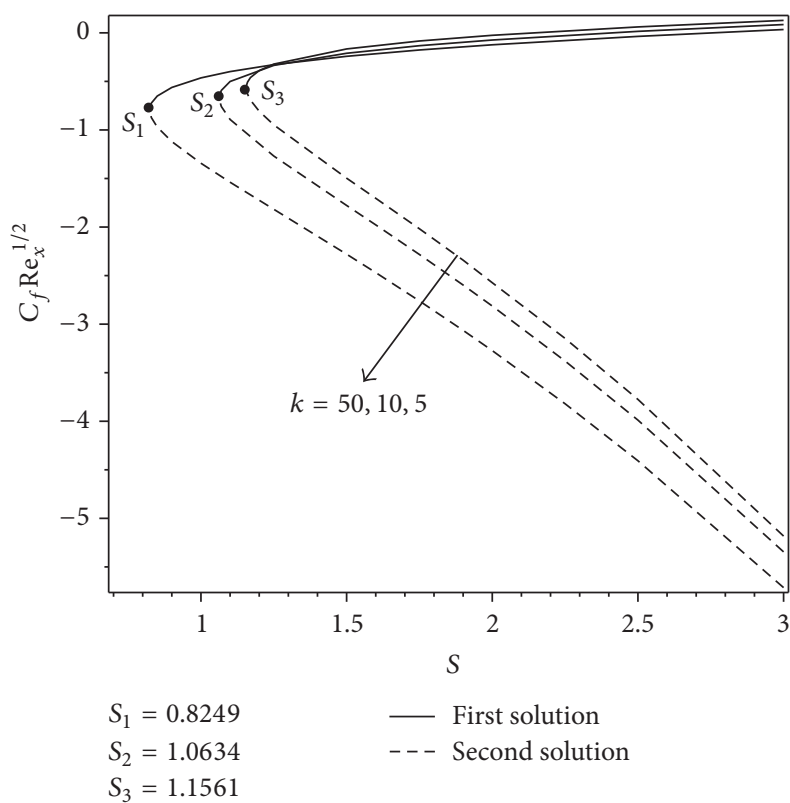

FIgURE 6: Variation of $C_{f} \operatorname{Re}_{x}{ }^{1 / 2}$ with $S$ for several values of $k$ when $K=1, \beta=-2, \lambda=-0.1$, and $n=0.5$ (weak concentration).

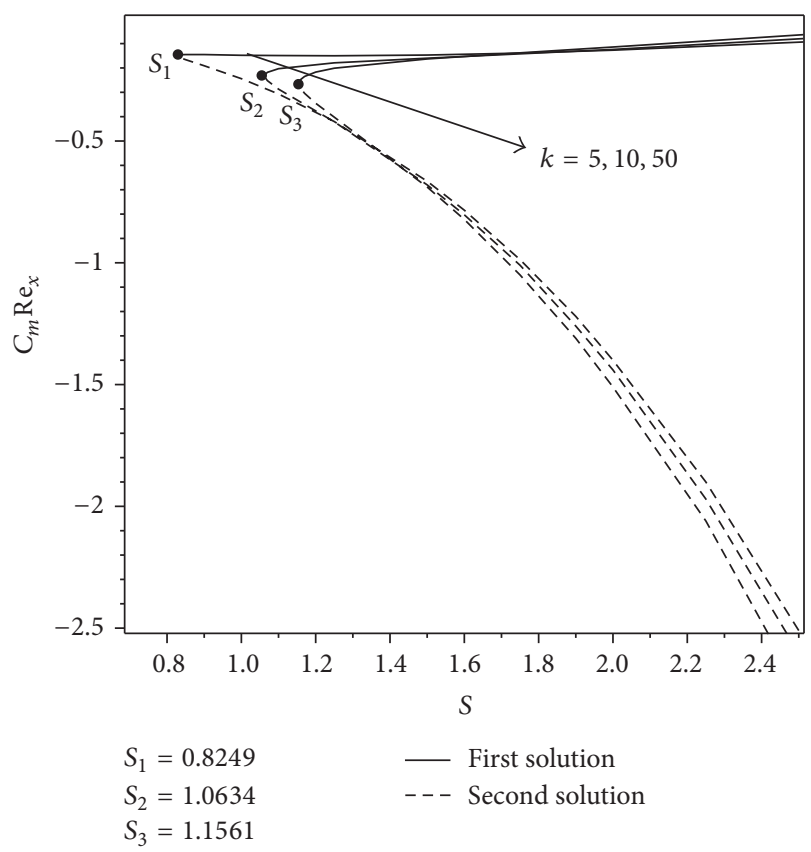

FIgURE 7: Variation of $C_{m} \operatorname{Re}_{x}$ with $S$ for several values of $k$ when $\beta=-2, K=1, \lambda=-0.1$ and $n=0.5$ (weak concentration).

velocity decreases when $K$ increase for both weak and strong concentration. An opposite observation has been described by Sajid et al. [34] on steady case, while microrotation velocity decreases with $K$ for strong concentration but increases for weak concentration (see Figures 11(a) and 11(b)). Sajid et al. [34] reported different outcome in both concentrations for steady case. Figures 12 and 13 represent the effects of $\beta$ on velocity and microrotation velocity profiles, respectively.

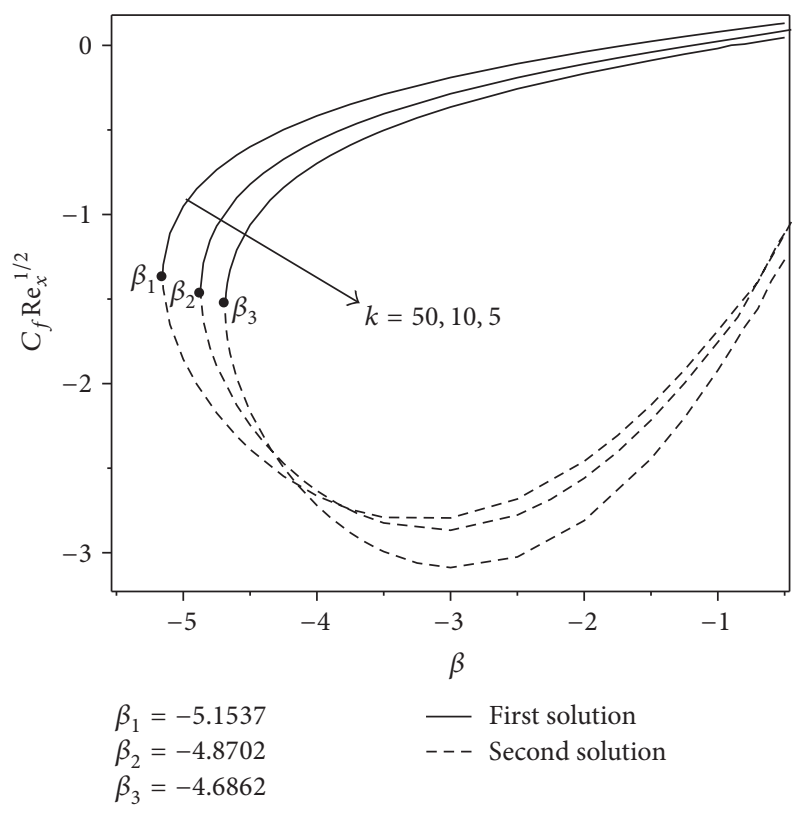

FIGURE 8: Variation of $C_{f} \operatorname{Re}_{x}{ }^{1 / 2}$ with $\beta$ for several values of $k$ when $S=2, \lambda=-0.1, K=1$, and $n=0$ (strong concentration).

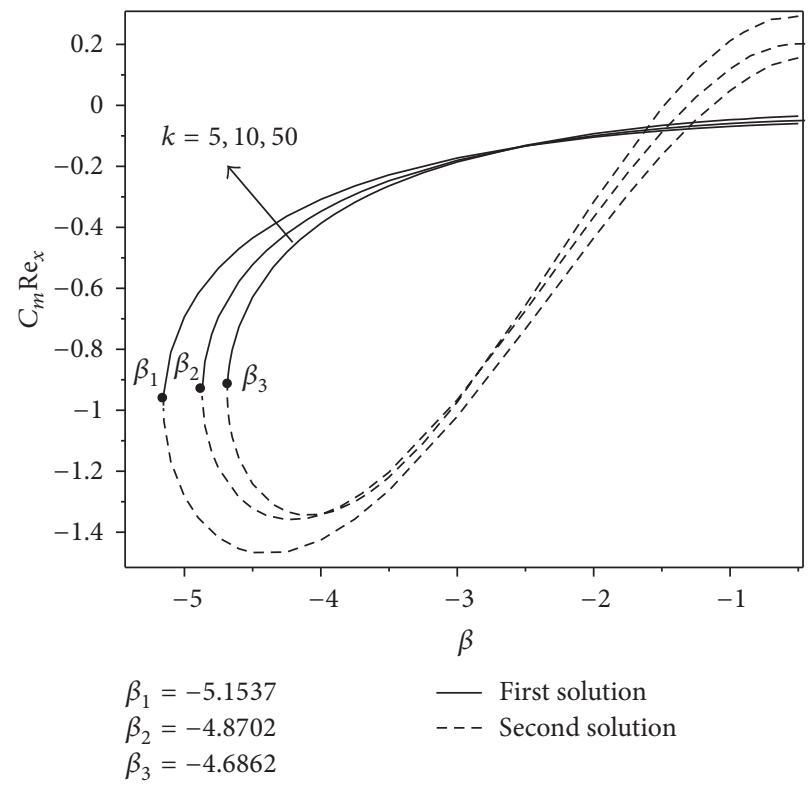

Figure 9: Variation of $C_{m} \operatorname{Re}_{x}$ with $\beta$ for several values of $k$ when $S=2, \lambda=-0.1, K=1$, and $n=0$ (strong concentration).

The boundary layer thicknesses for $f^{\prime}(\eta)$ and $g(\eta)$ increase with the increase of $\beta$ as illustrated in both Figures 12 and 13. Figure 12 shows a slight decrease of velocity profiles for weak concentration compared to the strong concentration. Figure 13(a) demonstrates that by increasing the unsteadiness parameter $\beta$ will increase $g(\eta)$ for strong concentration, but $g(\eta)$ decrease when $\beta$ increase (Figure 13(b)).

Then, we observed the effect of curvature parameter, $k$, on velocity and microrotation velocity profiles, figured in Figures 14 and 15. It shows a slight difference of first solution 


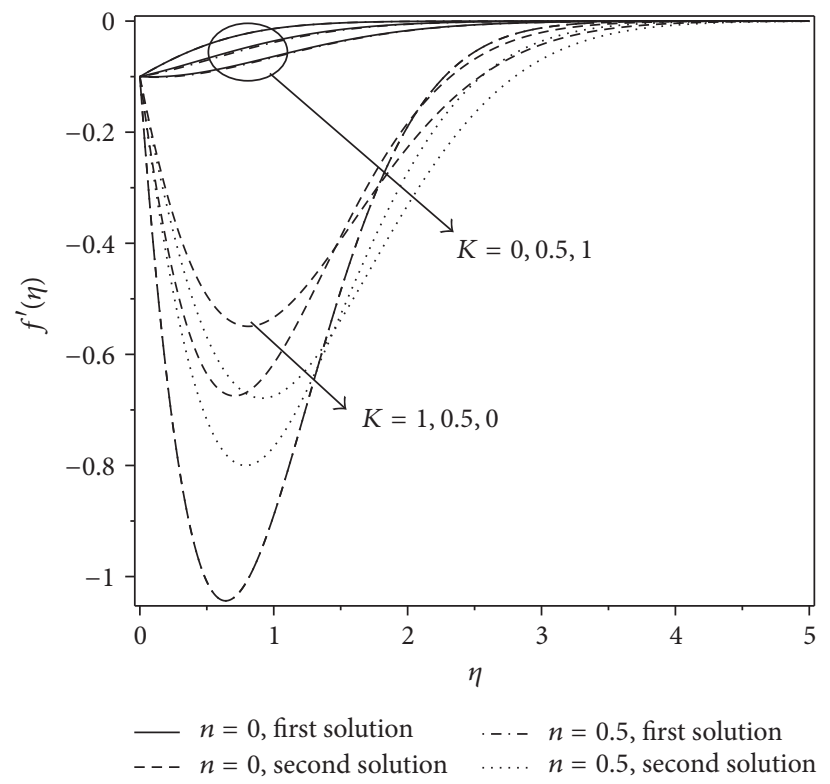

Figure 10: Effects of $K$ on the velocity profile $f^{\prime}(\eta)$ when $\beta=-2, S=2, k=50$, and $\lambda=-0.1$.

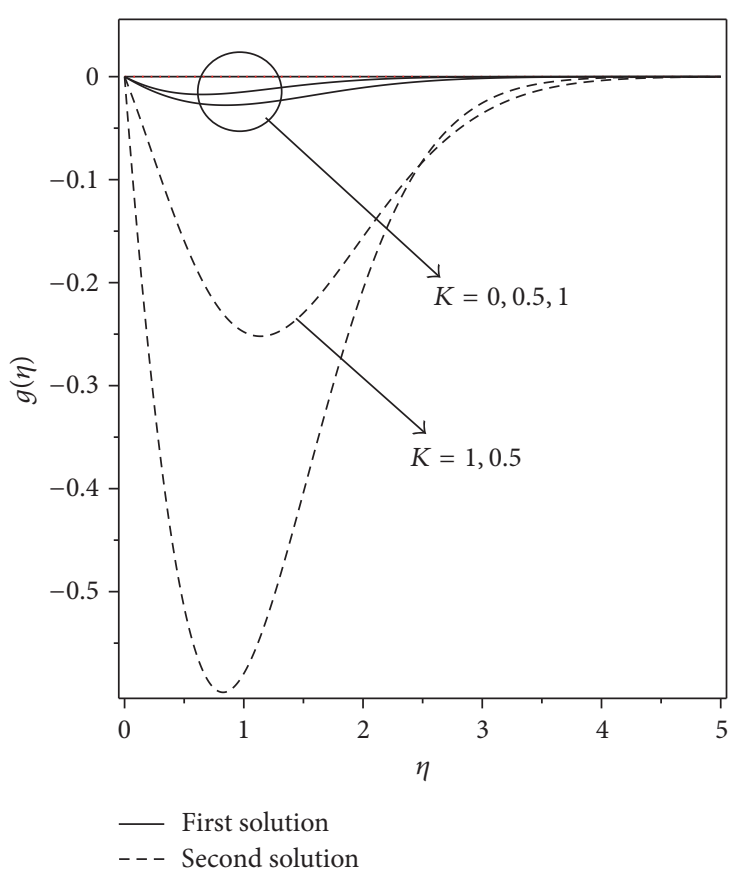

(a)

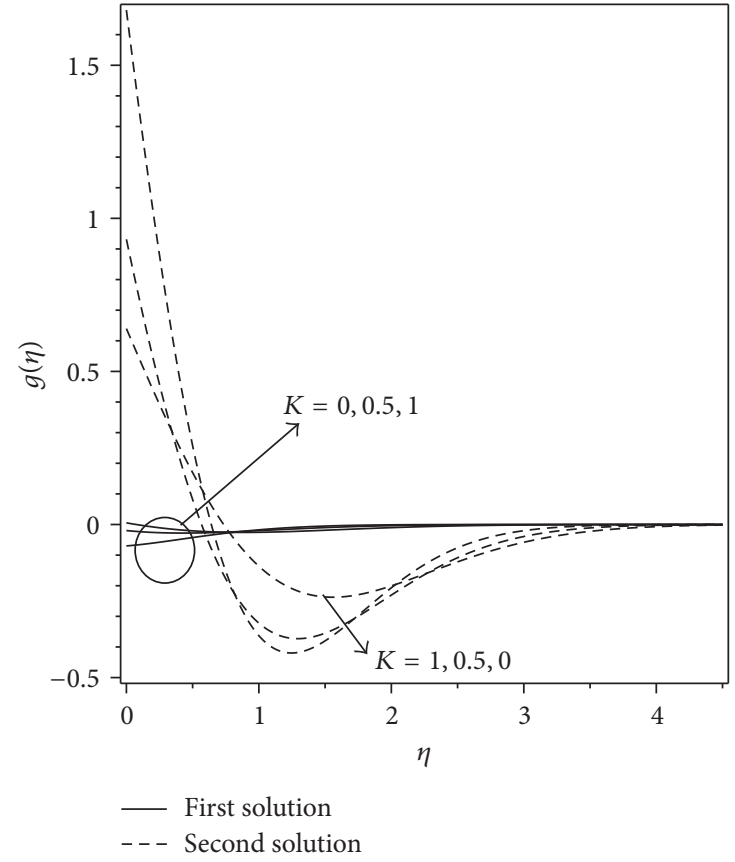

(b)

FIGURE 11: Effects of $K$ on the microrotation velocity profile $g(\eta)$ when $\beta=-2, S=2, k=50$, and $\lambda=-0.1$ : (a) $n=0$ (strong concentration); (b) $n=0.5$ (weak concentration).

compared to the second solution as $k$ changed. Increasing $k$ leads to an increasing of velocity profile in both weak and strong concentration. Similar result was observed by Sajid et al. [34] for steady case. Figure 15 describes that when $k$ increase, $g(\eta)$ increases for strong concentration but decreases for weak concentration. Influence of stretching and shrinking parameter, $\lambda$, on $f^{\prime}(\eta)$ and $g(\eta)$ is shown in Figures 16 and 17, respectively. Both figures show similar behavior where increasing $\lambda$ enhanced both velocity and microrotation velocity profiles for each weak and strong concentration. Figures 18 and 19 described the effects of constant mass flux, $S$, on the velocity and microrotation velocity profiles, respectively. Figure 18 explains that $f^{\prime}(\eta)$ increase with $S$ for both weak and strong concentration which happens because suction reduces drag force in order to avoid boundary layer separation. Furthermore, the velocity for weak concentration 


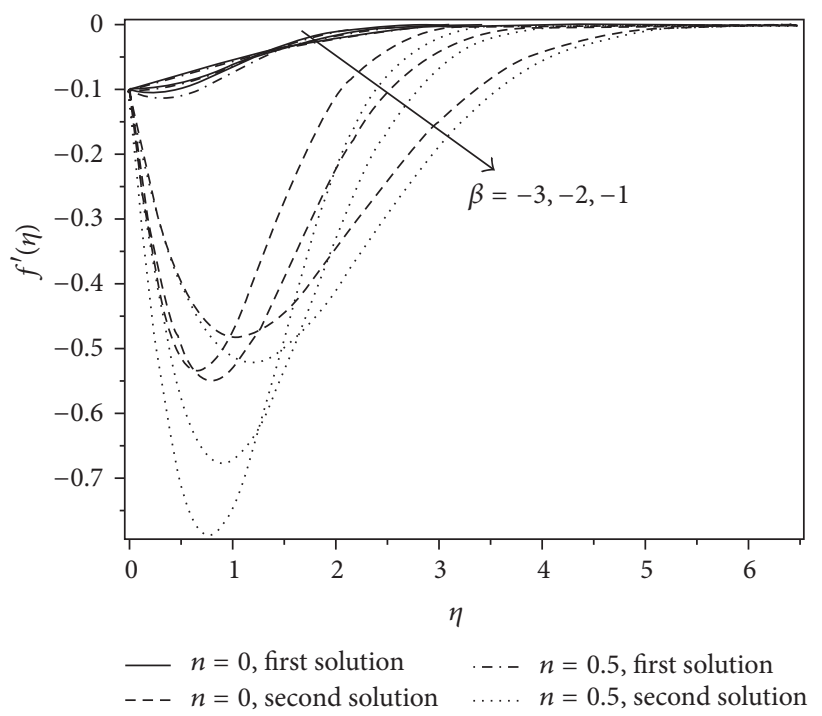

FIGURE 12: Effects of $\beta$ on the velocity profile $f^{\prime}(\eta)$ when $K=1, S=2, k=50$, and $\lambda=-0.1$.

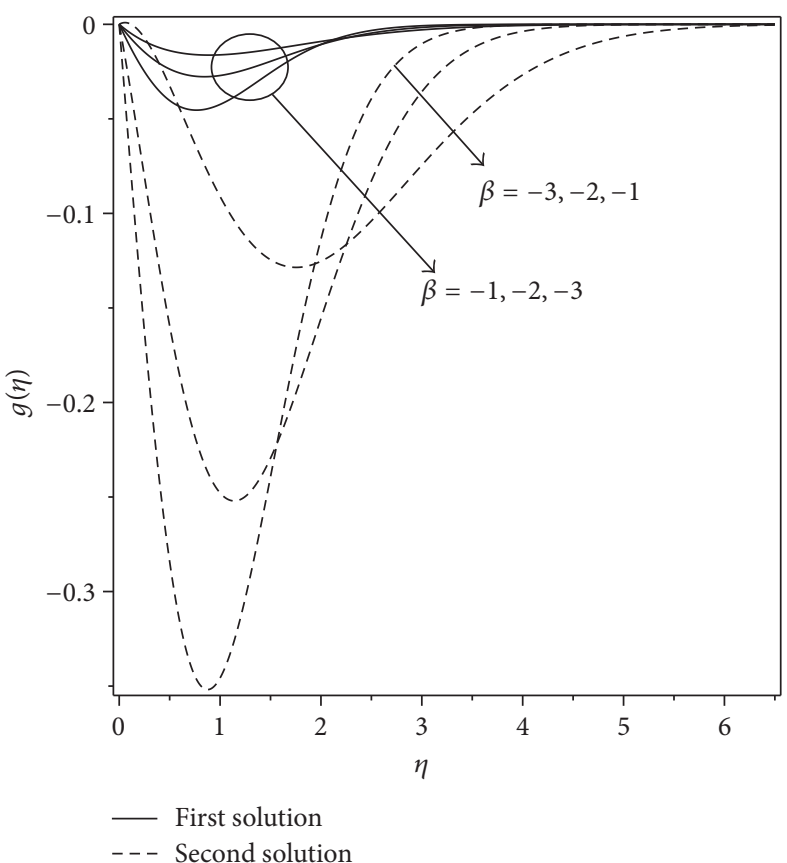

(a)

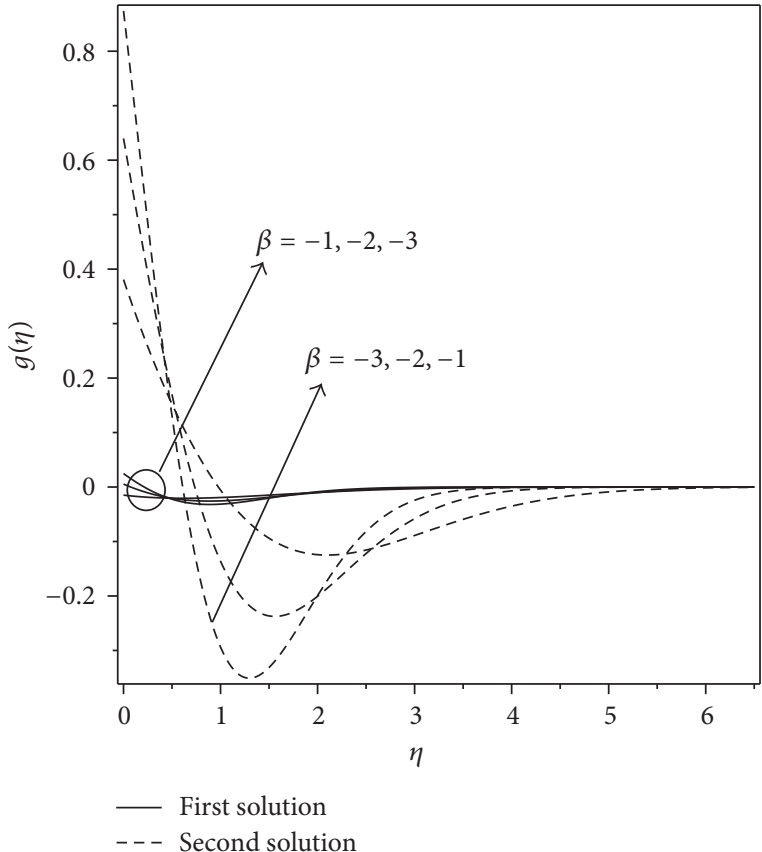

(b)

FiguRE 13: Effects of $\beta$ on the microrotation velocity profile $g(\eta)$ when $K=1, S=2, k=50$, and $\lambda=-0.1$ : (a) $n=0$ (strong concentration); (b) $n=0.5$ (weak concentration).

is slightly higher than the strong concentration when other parameters are identical. Figure 19(a) illustrates clearly that $g(\eta)$ increase when $S$ increases in strong concentration. Also, the boundary layer is getting thicker as $S$ decreases. Besides, increasing $S$ would decrease the microrotation velocity profile as shown in Figure 19(b). Generally, we noticed that the boundary layer thicknesses are larger for the second solutions than for the first solutions. All these profiles support the existence of dual nature of the solutions presented in Figures
2-9. They also satisfy the far field boundary conditions (12) asymptotically, which support the numerical results obtained.

\section{Conclusions}

An unsteady micropolar fluid flow over a permeable curved stretching and shrinking surface has been investigated. Numerical solutions of the developed mathematical problems are computed and discussed. It is noted that the boundary 


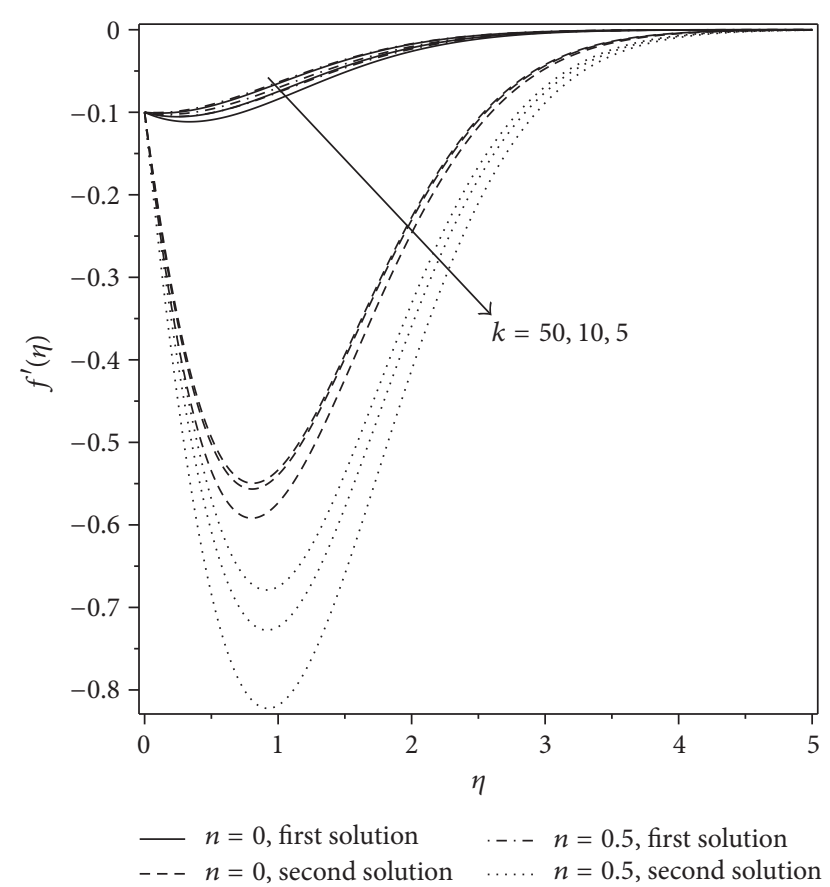

FIGURE 14: Effects of $k$ on the velocity profile $f^{\prime}(\eta)$ when $K=1, S=$ $2, \beta=-2$, and $\lambda=-0.1$.

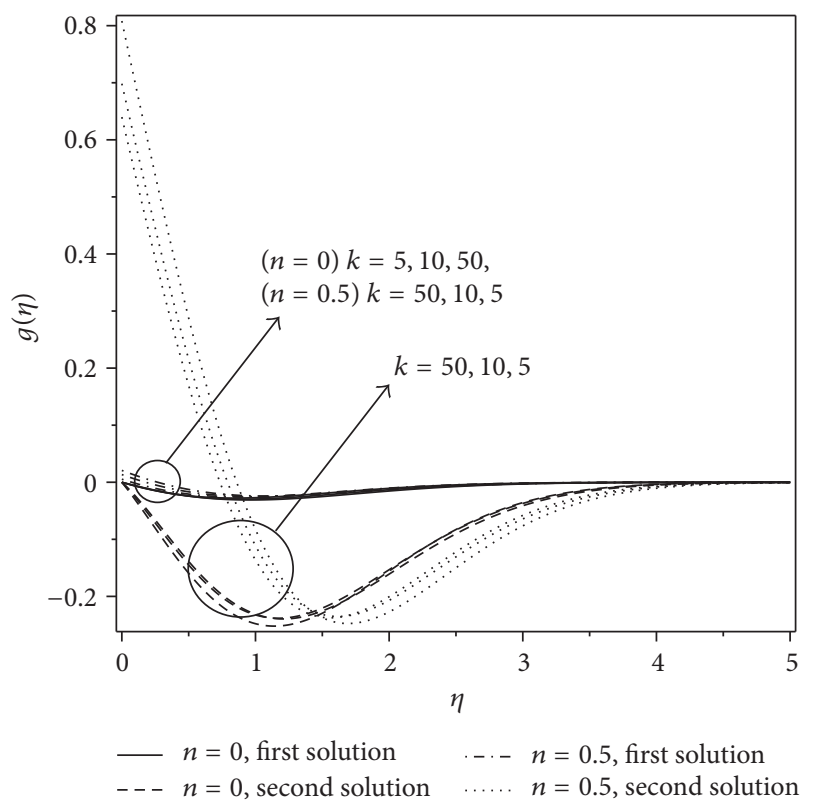

FIGURE 15: Effects of $k$ on the microrotation velocity profile $g(\eta)$ when $K=1, S=2, \beta=-2$, and $\lambda=-0.1$.

layer thickness increases for a curved sheet when compared to a flat sheet. The couple stress coefficients increase with $k$ for strong concentration $(n=0)$ but decrease in weak concentration $(n=0.5)$. The skin friction decreases when $K$ increase in both concentrations for shrinking case $(\lambda<0)$ but increase for stretching case $(\lambda>0)$. It is found that the solutions of the ordinary (similarity) differential equations

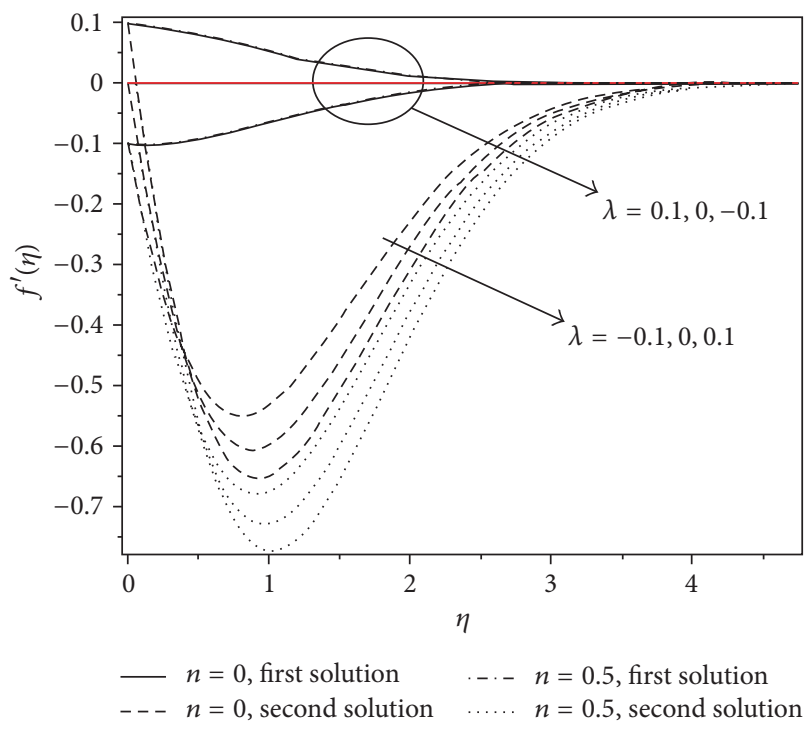

Figure 16: Effects of $\lambda$ on the velocity profile $f^{\prime}(\eta)$ when $K=1, S=$ $2, \beta=-2$, and $k=50$.

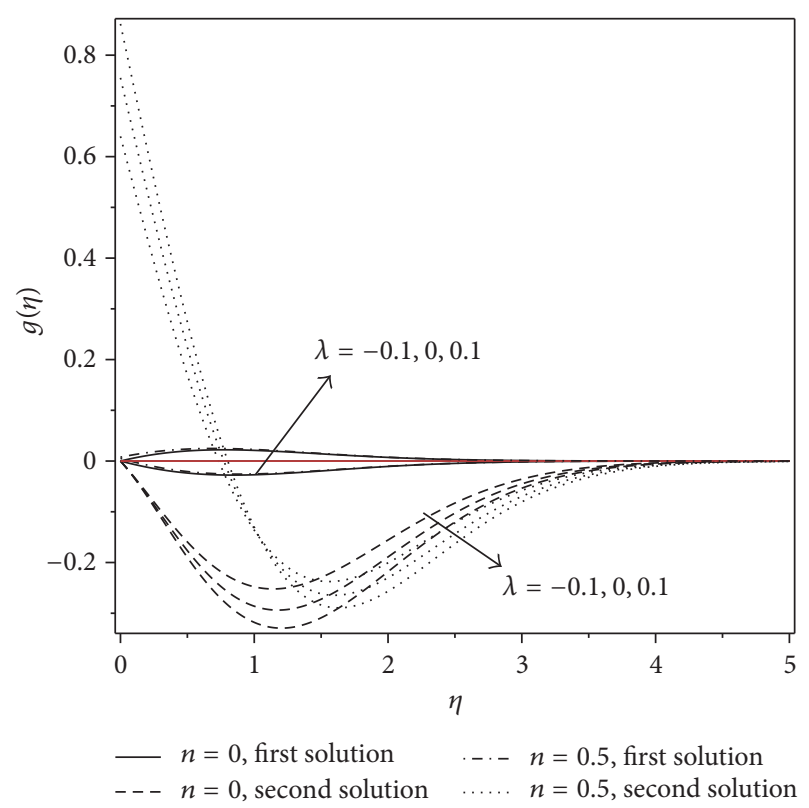

FIGURE 17: Effects of $\lambda$ on the microrotation velocity profile $g(\eta)$ when $K=1, S=2, \beta=-2$, and $k=50$.

have two branches, upper and lower branch solutions, in a certain range of the shrinking, mass suction, and unsteadiness parameters. The effects of the governing parameters on the skin friction coefficient, couple stress coefficients, dimensionless velocity profiles, and microrotation velocity profiles are presented graphically and discussed in detail. It results in that the curvature parameter affects considerably the flow characteristics. 


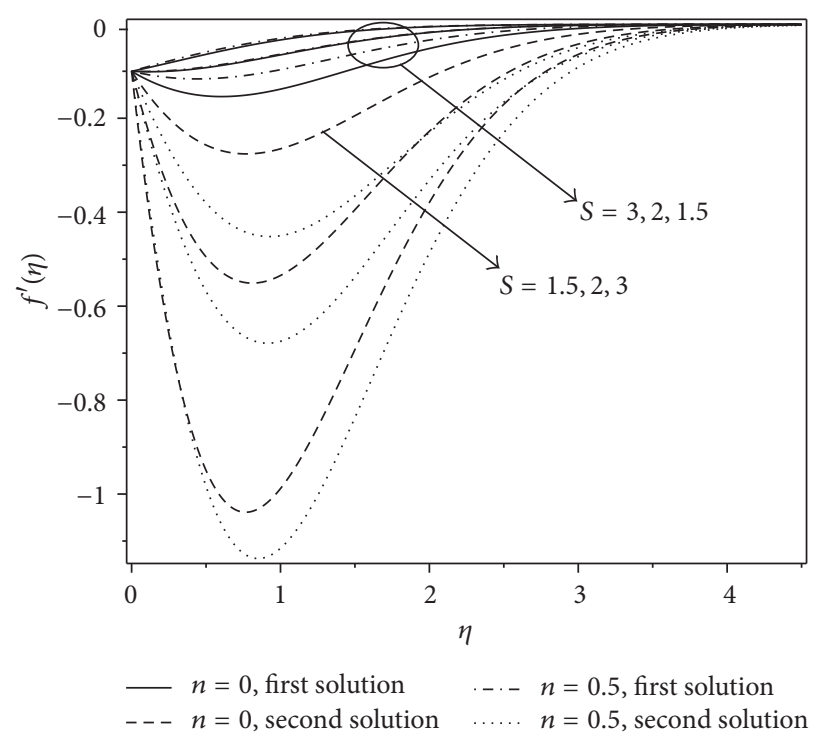

Figure 18: Effects of $S$ on the velocity profile $f^{\prime}(\eta)$ when $K=1, \beta=-2, k=50$, and $\lambda=-0.1$.

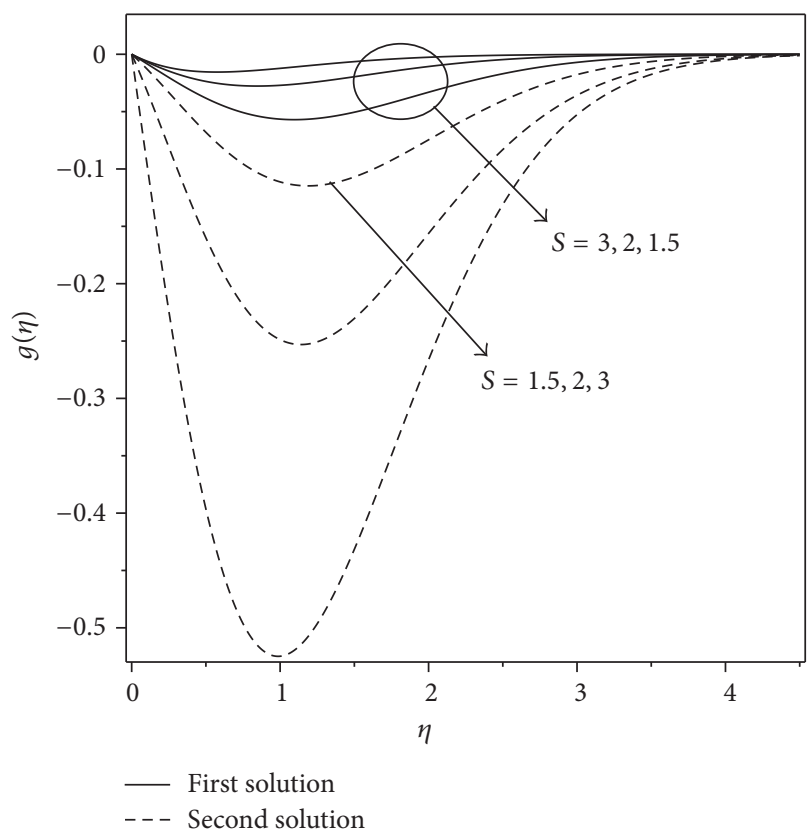

(a)

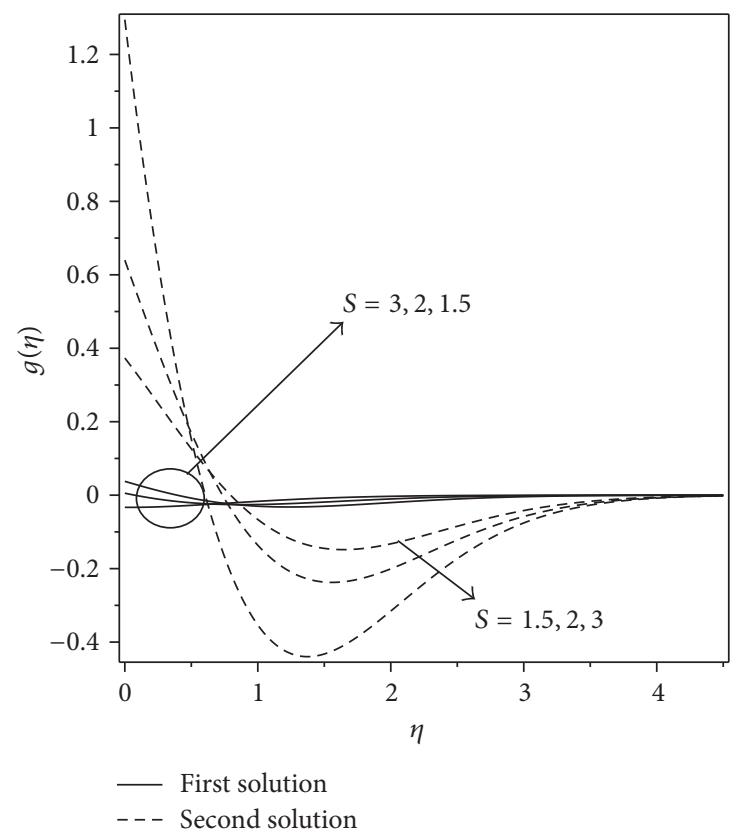

(b)

FIGURE 19: Effects of $S$ on the microrotation velocity profile $g(\eta)$ when $K=1, \beta=-2, k=50$, and $\lambda=-0.1$ : (a) $n=0$ (strong concentration); (b) $n=0.5$ (weak concentration).

\section{Nomenclature}

a: Constant

$C_{f}$ : Skin friction coefficient

$C_{m}$ : Couple stress coefficient

$j$ : $\quad$ Microinertia density

$k$ : Curvature parameter

$K$ : Micropolar or material parameter

$n$ : $\quad$ Ratio of the microrotation vector component and the fluid skin friction at the wall
$N$ : Microrotation or angular velocity

p: Pressure

$\mathrm{Re}_{x}$ : Local Reynolds number

$r, s$ : Curvilinear coordinates

$R: \quad$ Radius/distance of the sheet from origin

$R_{0}$ : Characteristic radius

$S$ : $\quad$ Constant mass flux

$t$ : Time

$u, v$ : Velocity component in the $x$ - and $y$-direction, respectively 
$u_{e}:$ External stream (inviscid flow)

$v_{w}$ : Mass flux velocity

$x, y$ : Cartesian coordinates along the surface and normal to it, respectively

$\alpha$ : Acceleration of the sheet

$\beta$ : Unsteadiness parameter

$\gamma: \quad$ Spin gradient viscosity

$\lambda$ : Velocity ratio parameter

$\eta$ : $\quad$ Pseudosimilarity variable

$\rho: \quad$ Density

$\tau_{w}:$ Skin friction or shear stress

$v$ : Kinematic viscosity.

\section{Superscript}

I: Differentiation with respect to $\eta$

\section{Subscript}

c: Critical value

$w$ : Condition at the wall

$\infty$ : Condition at infinity.

\section{Competing Interests}

The authors declare that they have no competing interests.

\section{Acknowledgments}

The authors gratefully acknowledge the financial supports received in the form of research grants fund from the Ministry of Higher Education, Malaysia.

\section{References}

[1] A. C. Eringen, “Theory of micropolar fluids," Journal of Applied Mathematics and Mechanics, vol. 16, pp. 1-18, 1966.

[2] A. C. Eringen, "Theory of thermomicropolar fluids," Journal of Mathematical Analysis and Applications, vol. 38, pp. 480-496, 1972.

[3] T. Ariman, M. A. Turk, and N. D. Sylvester, "Applications of microcontinuum fluid mechanics," International Journal of Engineering Science, vol. 12, no. 4, pp. 273-293, 1974.

[4] G. Ahmadi, "Self-similar solution of imcompressible micropolar boundary layer flow over a semi-infinite plate," International Journal of Engineering Science, vol. 14, no. 7, pp. 639-646, 1976.

[5] G. S. Guram and A. C. Smith, "Stagnation flows of micropolar fluids with strong and weak interactions," Computers \& Mathematics with Applications, vol. 6, no. 2, pp. 213-233, 1980.

[6] R. S. R. Gorla, "Micropolar boundary layer flow at a stagnation point on a moving wall," International Journal of Engineering Science, vol. 21, no. 1, pp. 25-33, 1983.

[7] L. J. Crane, "Flow past a stretching plate," Zeitschrift für Angewandte Mathematik und Physik ZAMP, vol. 21, no. 4, pp. 645-647, 1970.

[8] C. Y. Wang, "The three-dimensional flow due to a stretching flat surface," The Physics of Fluids, vol. 27, no. 8, pp. 1915-1917, 1984.

[9] C. Y. Wang, "Analysis of viscous flow due to a stretching sheet with surface slip and suction," Nonlinear Analysis: Real World Applications, vol. 10, no. 1, pp. 375-380, 2009.
[10] T. R. Mahapatra and A. S. Gupta, "Stagnation-point flow towards stretching surface," Canadian Journal of Chemical Engineering, vol. 81, no. 2, pp. 258-263, 2003.

[11] T. R. Mahapatra and A. S. Gupta, "Magnetohydrodynamic stagnation-point flow towards a stretching sheet," Acta Mechanica, vol. 152, no. 1-4, pp. 191-196, 2001.

[12] T. R. Mahapatra, S. K. Nandy, and A. S. Gupta, "Analytical solution of magnetohydrodynamic stagnation-point flow of a power-law fluid towards a stretching surface," Applied Mathematics and Computation, vol. 215, no. 5, pp. 1696-1710, 2009.

[13] M. H. Mat Yasin, A. Ishak, and I. Pop, "MHD heat and mass transfer flow over a permeable stretching/shrinking sheet with radiation effect," Journal of Magnetism and Magnetic Materials, vol. 407, pp. 235-240, 2016.

[14] M. Turkyilmazoglu, "Mixed convection flow of magnetohydrodynamic micropolar fluid due to a porous heated/cooled deformable plate: exact solutions," International Journal of Heat and Mass Transfer, vol. 106, pp. 127-134, 2017.

[15] W. Ibrahim and B. Shankar, "MHD boundary layer flow and heat transfer of a nanofluid past a permeable stretching sheet with velocity, thermal and solutal slip boundary conditions," Computers \& Fluids, vol. 75, pp. 1-10, 2013.

[16] N. Bachok, A. Ishak, and I. Pop, "Unsteady boundary-layer flow and heat transfer of a nanofluid over a permeable stretching/shrinking sheet," International Journal of Heat and Mass Transfer, vol. 55, no. 7-8, pp. 2102-2109, 2012.

[17] K. Zaimi, A. Ishak, and I. Pop, "Flow past a permeable stretching/shrinking sheet in a nanofluid using two-phase model," PLoS ONE, vol. 9, no. 11, Article ID el11743, 2014.

[18] M. Turkyilmazoglu, "Flow of a micropolar fluid due to a porous stretching sheet and heat transfer," International Journal of NonLinear Mechanics, vol. 83, pp. 59-64, 2016.

[19] M. Miklavčič and C. Y. Wang, "Viscous flow due to a shrinking sheet," Quarterly of Applied Mathematics, vol. 64, no. 2, pp. 283290, 2006.

[20] C. Y. Wang, "Stagnation flow towards a shrinking sheet," International Journal of Non-Linear Mechanics, vol. 43, no. 5, pp. 377-382, 2008.

[21] S. Goldstein, "On backward boundary layers and flow in converging passages," Journal of Fluid Mechanics, vol. 21, no. 1, pp. 33-45, 1965.

[22] M. Turkyilmazoglu, "A note on micropolar fluid flow and heat transfer over a porous shrinking sheet," International Journal of Heat and Mass Transfer, vol. 72, pp. 388-391, 2014.

[23] H. Rosali, A. Ishak, R. Nazar, and I. Pop, "Rotating flow over an exponentially shrinking sheet with suction," Journal of Molecular Liquids, vol. 211, pp. 965-969, 2015.

[24] S. Naramgari and C. Sulochana, "MHD flow over a permeable stretching/shrinking sheet of a nanofluid with suction/injection," Alexandria Engineering Journal, vol. 55, no. 2, pp. 819-827, 2016.

[25] J. H. Merkin, Y. Y. Lok, and I. Pop, "A note on the stagnationpoint flow over a permeable shrinking sheet with slip effects," International Communications in Heat and Mass Transfer, vol. 71, pp. 101-107, 2016.

[26] S. K. Soid, S. A. Kechil, and A. Ishak, "Axisymmetric stagnationpoint flow over a stretching/shrinking plate with second-order velocity slip," Propulsion and Power Research, vol. 5, no. 3, pp. 194-201, 2016.

[27] N. C. Roşca and I. Pop, "Boundary layer flow past a permeable shrinking sheet in a micropolar fluid with a second order slip 
flow model," European Journal of Mechanics-B/Fluids, vol. 48, pp. 115-122, 2014.

[28] Aurangzaib, K. Bhattacharyya, and S. Shafie, "Effect of partial slip on an unsteady MHD mixed convection stagnation-point flow of a micropolar fluid towards a permeable shrinking sheet," Alexandria Engineering Journal, vol. 55, no. 2, pp. 1285-1293, 2016.

[29] T. Fang, S. Yao, J. Zhang, and A. Aziz, "Viscous flow over a shrinking sheet with a second order slip flow model," Communications in Nonlinear Science and Numerical Simulation, vol. 15, no. 7, pp. 1831-1842, 2010.

[30] K. Bhattacharyya, S. Mukhopadhyay, and G. C. Layek, "Slip effects on boundary layer stagnation-point flow and heat transfer towards a shrinking sheet," International Journal of Heat and Mass Transfer, vol. 54, no. 1-3, pp. 308-313, 2011.

[31] Z. Abbas, M. Naveed, and M. Sajid, "Heat transfer analysis for stretching flow over a curved surface with magnetic field," Journal of Engineering Thermophysics, vol. 22, no. 4, pp. 337-345, 2013.

[32] N. C. Roşca and I. Pop, "Unsteady boundary layer flow over a permeable curved stretching/shrinking surface," European Journal of Mechanics-B/Fluids, vol. 51, pp. 61-67, 2015.

[33] M. Sajid, N. Ali, T. Javed, and Z. Abbas, "Stretching a curved surface in a viscous fluid," Chinese Physics Letters, vol. 27, no. 2, Article ID 024703, 2010.

[34] M. Sajid, N. Ali, Z. Abbas, and T. Javed, "Flow of a micropolar fluid over a curved stretching surface," Journal of Engineering Physics and Thermophysics, vol. 84, no. 4, pp. 864-871, 2011.

[35] Z. Abbas, M. Naveed, and M. Sajid, "Hydromagnetic slip flow of nanofluid over a curved stretching surface with heat generation and thermal radiation," Journal of Molecular Liquids, vol. 215, pp. 756-762, 2016.

[36] M. Imtiaz, T. Hayat, A. Alsaedi, and A. Hobiny, "Homogeneousheterogeneous reactions in MHD flow due to an unsteady curved stretching surface," Journal of Molecular Liquids, vol. 221, pp. 245-253, 2016.

[37] D. P. Telionis, Unsteady Viscous Flows, Springer, 1981.

[38] M. Naveed, Z. Abbas, and M. Sajid, "Hydromagnetic flow over an unsteady curved stretching surface," Engineering Science and Technology, vol. 19, no. 2, pp. 841-845, 2016.

[39] P. D. Weidman, D. G. Kubitschek, and A. M. J. Davis, "The effect of transpiration on self-similar boundary layer flow over moving surfaces," International Journal of Engineering Science, vol. 44, no. 11-12, pp. 730-737, 2006. 


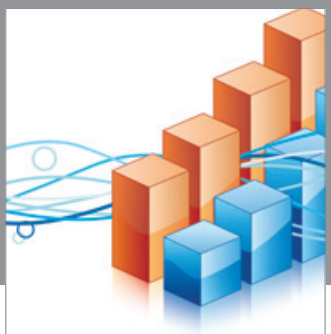

Advances in

Operations Research

vatem alat4

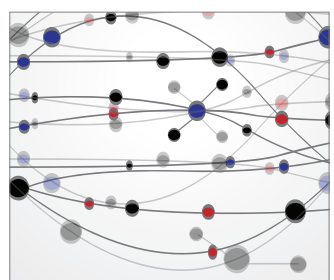

\section{The Scientific} World Journal
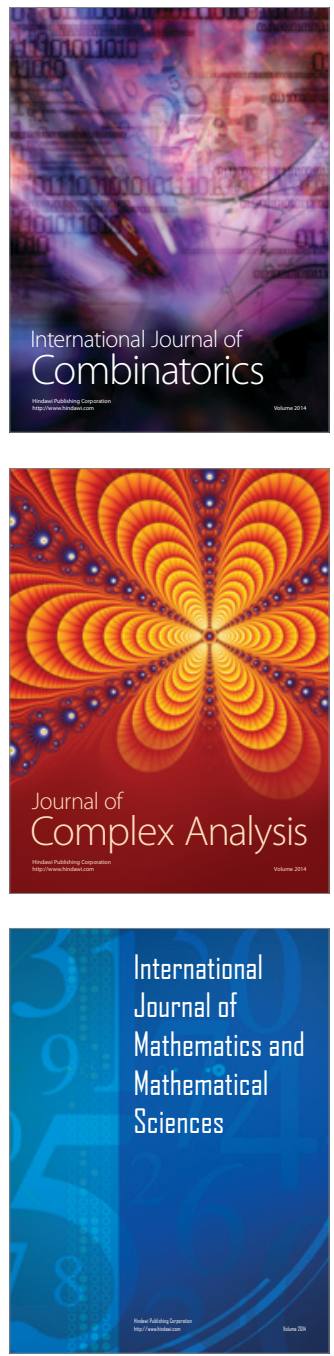
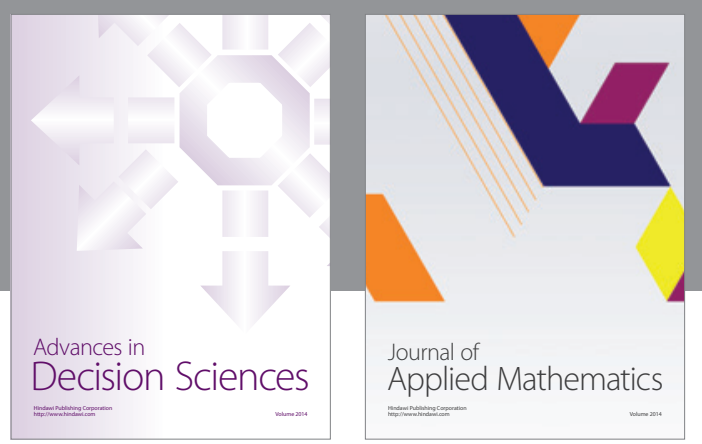

Algebra

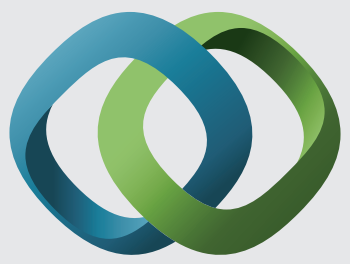

\section{Hindawi}

Submit your manuscripts at

https://www.hindawi.com
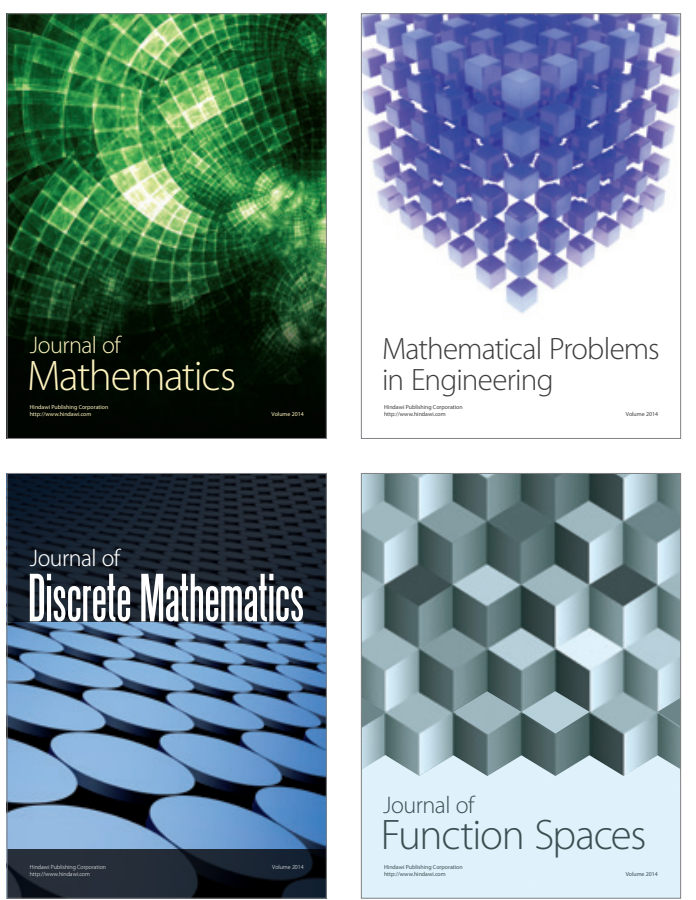

Mathematical Problems in Engineering
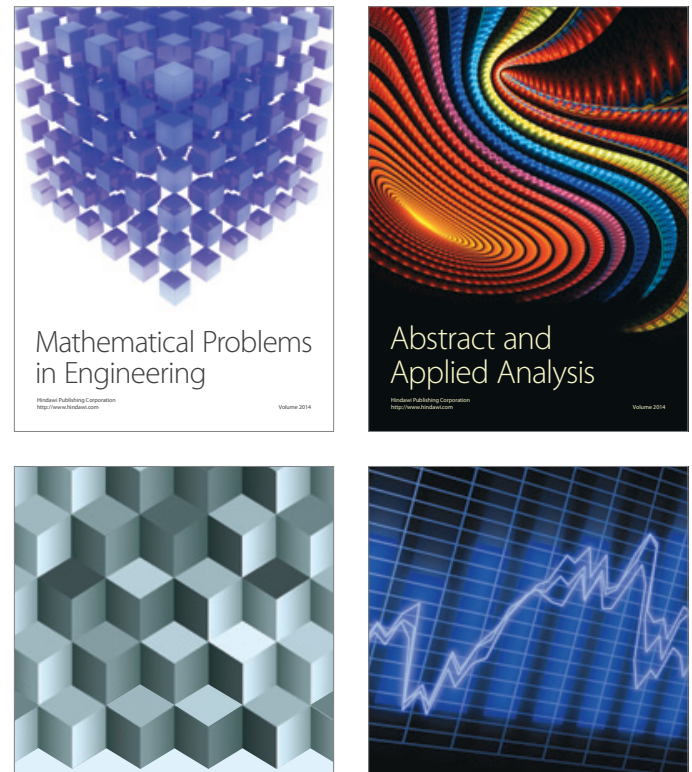

Journal of

Function Spaces

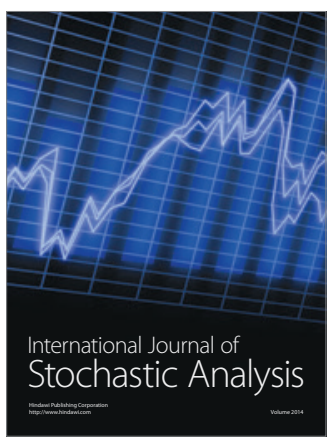

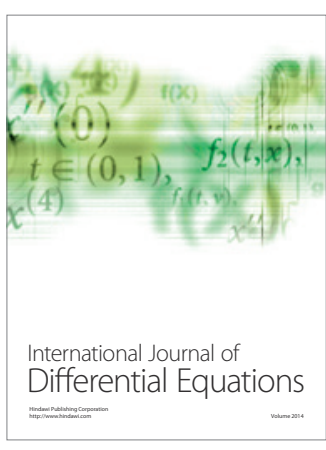
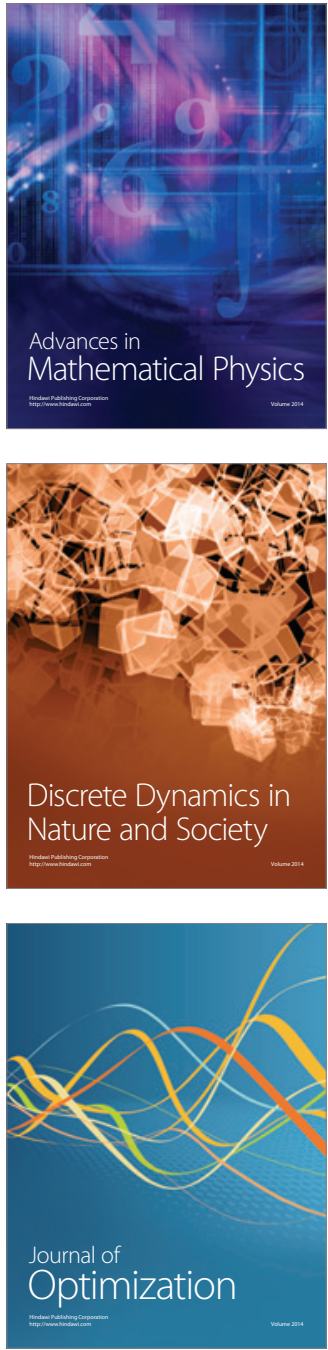